\title{
Retraction Note to: Simulation Study of Dynamic Characteristics of Hot Pepper Harvester
}

\author{
Seokho Kang ${ }^{1} \cdot$ Junhee Kim ${ }^{1} \cdot$ Yeongsu Kim ${ }^{1} \cdot$ Yushin $\mathrm{Ha}^{1} \cdot$ Seungmin Woo ${ }^{1}$ \\ Published online: 25 August 2021 \\ (C) The Korean Society for Agricultural Machinery 2021
}

Retraction note to: Journal of Biosystems Engineering (2020) 45:333-340

https://doi.org/10.1007/s42853-020-00074-7

The Editor-in-Chief has retracted this article at the request of Seungmin Woo. This article significantly overlaps with an article by the same authors which was previously published in Korean (Kang et al. 2020).

All authors agree to this retraction.

\section{Reference}

Kang, S., Kim, J., Kim, Y., Woo, S., Daniel, D. U., \& Ha, Y. (2020). 시뮬 레이션을 이용한 고추 수확기의 동적 특성 연구. 한국시뮬레이션학회논문 지, 29(3), 19-25. https://doi.org/10.9709/JKSS.2020.29. 3.019

The online version of the original article can be found at https://doi.org/ 10.1007/s42853-020-00074-7

Yushin Ha

yushin72@knu.ac.kr

$\triangle$ Seungmin Woo

kooger7571@naver.com

1 Kyungpook National University, 106, College of Agriculture, Building 3, 80, Daehak-ro, Buk-gu, Daegu, Republic of Korea 